\title{
Identifikasi Masalah Dan Model Pengelolaan Wilayah Pesisir Desa Labuhan Sumbawa, Kecamatan Labuhan Badas, Sumbawa
}

\section{Identification Of Problems And Models Of Coastal Area Management Labuhan Village Sumbawa, District Labuhan Badas, Sumbawa}

\author{
Ieke Wulan $\mathrm{Ayu}^{1 *}, \mathrm{Usman}^{2}, \mathrm{Edrial}^{3}, \mathrm{Soemarno}^{4}$ \\ ${ }^{1}$ Program Studi Agroteknologi, Fakultas Pertanian,Universitas Samawa, Jalan Bypass Sering, \\ Sumbawa Besar, Nusa Tenggara Barat, Indonesia. 0000-0003-2864-9293 \\ ${ }^{2}$ Program Studi Ekonomi Pembangunan, Fakultas Ekonomi dan Manajemen,Universitas \\ Samawa, Jalan Bypass Sering, Sumbawa Besar, Nusa Tenggara Barat, Indonesia. \\ ${ }^{3}$ Program Studi Ilmu Administrasi Negara, Fakultas Ilmu Sosial dan Ilmu Politik,Universitas \\ Samawa, Jalan Bypass Sering, Sumbawa Besar, Nusa Tenggara Barat, Indonesia. \\ ${ }^{4}$ Jurusan Ilmu Tanah, Universitas Brawijaya Malang, Jalan Veteran, Ketawanggede, Kecamatan \\ Lowokwaru, Kota Malang, Jawa Timur, Indonesia. \\ *Correspondent Author : iekewulanayu002@gmail.com
}

Submitted: 22 June 2021 Revised: 09 July 2021 Accepted: 16 July 2021

Publish: 31 July 2021

\begin{abstract}
Abstrak
Wilayah pesisir Desa Labuhan Sumbawa memiliki nilai strategis bagi pengembangan ekonomi dan peningkatan kesejahteraan masyarakat, namun sangat rentan terhadap kerusakan akibat pemanfaatan ruang yang multifungsi, sehingga sangat dibutuhkan pengelolaan pesisir yang berfokus pada karakteristik wilayah, dengan menempatkan tiga pilar pembangunan berkelanjutan yaitu ekologi, ekonomi, dan sosial. Penelitian bertujuan untuk mengidentifikasi masalah dan model pengelolaan wilayah pesisir di Desa Labuhan Sumbawa, Kecamatan Labuhan Badas, Sumbawa. Metode penelitian yang digunakan yaitu metode penelitian deskriptif. Pengumpulan data dilakukan dengan metode observasi dan wawancara semi terstruktur. Teknik pengambilan sampel secara accidental dan analisis data secara kualitatif. Hasil penelitian menunjukkan bahwa di wilayah pesisir lokasi penelitian, teridentifikasi: (1) Masalah kerusakan fisik lingkungan, meliputi: a) Kerusakan ekosistem (ekosistem, terumbu karang, padang lamun, dan pantai); b) Kerusakan sumber daya ikan; c) Pencemaran; d) Abrasi, sedimentasi, dan siltasi; dan d) Bencana alam (banjir).; (2) Masalah sosial ekonomi, meliputi: a) Masalah kemiskinan dan rendahnya tingkat pendidikan penduduk; b) Keterbatasan dana dalam pembangunan; dan c) Kurangnya pemahaman terhadap nilai sumber daya wilayah pesisir; (3) Masalah kelembagaan, meliputi: a) Masalah konflik kewenangan, yang dapat terjadi karena pembangunan yang bersifat sektoral; b) Masalah ketidakpastian hukum. Model pengelolaan wilayah pesisir yang dapat diterapkan, yaitu: (1) Pengelolaan tradisional; (2) Pengelolaan sumber daya kawasan pesisir berbasis masyarakat; (3) Co-management, dan; (4) Pengelolaan sumber daya perikanan berbasis ekosistem (Ecosystem Based Fisheries Management/EBFM). Kesimpulan penelitian yaitu kerusakan wilayah pesisir akan berdampak terhadap kondisi ekologi, ekonomi, dan sosial sehingga pelibatan multipihak sangat penting dalam pengelolaan wilayah pesisir yang berkelanjutan.
\end{abstract}

Kata kunci: Ekologi, ekonomi, sosial, pesisir,model

Abstract

The coastal area of Labuhan Sumbawa Village has strategic value for economic development and improving people's welfare, but is very vulnerable to damage due to the use of multifunctional space, so that coastal management is urgently needed that focuses on regional characteristics, by placing three pillars of sustainable development, namely ecology, economy, and social. This study aims to identify problems and models of coastal area management in Labuhan Sumbawa Village, Labuhan Badas District, Sumbawa. The research method used is descriptive research method. Data was collected by means of observation and semi-structured interviews. Accidental sampling technique and qualitative data analysis. The results showed that in the coastal area of the research location, identified: (1) Physical damage to the 
environment, including: a) Damage to ecosystems (ecosystems, coral reefs, seagrass beds, and beaches); b) Damage to fish resources; c) Pollution; d) Abrasion, sedimentation, and siltation; and d) Natural disasters (floods); (2) Socio-economic problems, including: a) The problem of poverty and the low level of education of the population; b) Limited funds in development; and c) Lack of understanding of the value of coastal area resources; (3) Institutional problems, including: a) The problem of conflict of authority, which can occur due to sectoral development; b) The problem of legal uncertainty. The coastal area management models that can be applied are: (1) traditional management; (2) community-based coastal area resource management; (3) Co-management, and; (4) Ecosystem Based Fisheries Management (EBFM). The conclusion of the study is that damage to coastal areas will have an impact on ecological, economic, and social conditions so that multi-stakeholder involvement is very important in sustainable coastal area management.

Keywords: Ecology, economy, social, coastal, model

\section{PENDAHULUAN}

Propinsi Nusa Tenggara Barat (Prop.NTB) memiliki luas 49.312,19 $\mathrm{Km}^{2}$, terdiri dari dua buah pulau besar yaitu Pulau Lombok yang memiliki luas daratan 4.738,65 $\mathrm{Km}^{2}$ dan pulau Sumbawa memiliki luas daratan \pm $15.414,50 \mathrm{Km}^{2}$ serta 278 pulau-pulau kecil. Panjang garis pantai Provinsi Nusa Tenggara Barat $\pm 2.332,80 \mathrm{Km}$ (Pulau Lombok dengan garis pantai $514 \mathrm{~km}$ dan Pulau Sumbawa dengan garis pantai $1.758,80 \mathrm{~km}$ ). Prop.NTB secara biofisik, mempunyai potensi sumberdaya pesisir dan laut yang cukup tinggi, yaitu luas perairan lautnya sekitar $29.159,04 \mathrm{~km}^{2}$ dan perairan karang sekitar $3.601 \mathrm{~km}^{2}$.

Wilayah laut yang luas dari wilayah daratan, menjadikan sumber daya pesisir dan lautan bernilai ekonomis dan ekologis yang tinggi. UU No. 27 Tahun 2007 tentang Pengelolaan Wilayah Pesisir dan
Pulau-Pulau Kecil sebagaimana telah diubah dengan UU No. 1 Tahun 2014, dalam Pasal 1 angka 2 UU tersebut mendefinisikan wilayah pesisir sebagai daerah peralihan antara ekosistem darat dan laut yang dipengaruhi oleh perubahan di darat dan laut. Pasal 2 menyebutkan bahwa ruang lingkup pengaturan wilayah pesisir dan pulau-pulau kecil meliputi daerah peralihan antara ekosistem darat dan laut yang dipengaruhi oleh perubahan di darat dan laut, ke arah darat mencakup wilayah administrasi kecamatan dan ke arah laut sejauh 12 (dua belas) mil laut di ukur dari garis pantai.

Pada abad ke-20, negara-negara pesisir telah mengalihkan pusat pembangunan ekonomi ke wilayah pesisir, dan hampir $50 \%$ populasi global telah menetap di wilayah dalam jarak $100 \mathrm{~km}$ dari garis pantai (Li et al., 2018). Perpindahan pusat-pusat 
ekonomi tersebut menyebabkan perubahan yang cepat pada sumberdaya garis pantai, yang berdampak besar pada aspek ekonomi, sosial, ekologi, dan lingkungan wilayah pesisir (Switzer et al., 2012). Garis pantai adalah batas antara kontak laut dan darat (Mujabar,2011), kaya sumberdaya hayati dan non hayati (Sandhyavitri et al., 2019; Sui et al., 2020), basis kelangsungan hidup dan pembangunan sumberdaya alam dan manusia (Huang,2010) yang memiliki keragaman fungsional (Liao et al., 2016), regional (Wang et al.,2019; Sun et al., 2019).

Garis pantai memiliki ketidakstabilan sebagai sumber daya yang berharga di wilayah pesisir (Hou, 2016; Salmon,2019), rentan terhadap proses alam dan proses manusia seperti pertumbuhan perkotaan, pengembangan sumber daya, dan pelepasan polusi. Penggunaan garis pantai yang berlebihan, koreksi buatan dari garis pantai yang melengkung secara alami, dan budidaya yang tidak teratur telah merusak lingkungan ekologi daerah pantai. Pemantauan garis pantai telah menjadi tugas penting untuk pembangunan berkelanjutan dan perlindungan lingkungan (Sener et al., 2009; Zhu et al 2012).

Desa Labuhan Sumbawa, Kecamatan Labuhan Badas merupakan wilayah pesisir yang berada di Kabupaten Sumbawa, Prop.NTB. Wilayah pesisir Desa Labuhan Sumbawa memiliki nilai strategis bagi pengembangan ekonomi dan peningkatan kesejahteraan masyarakat, namun sangat rentan terhadap kerusakan. Perubahan yang terjadi pada wilayah pesisir dan laut tidak hanya sekedar gejala alam, namun dipengaruhi oleh aktifitas manusia yang ada di sekitarnya. Wilayah pesisir Labuhan Sumbawa merupakan wilayah penerima tekanan lebih besar dibandingkan dengan wilayah lain, karena wilayah pesisir mempunyai fungsi sebagai penyedia sumberdaya alam, jasa-jasa pendukung kehidupan, jasa kenyamanan dan sebagai penerima limbah dari aktivitas pembangunan yang terdapat di daratan berdampak terhadap kualitas lingkungan wilayah pesisir terutama pada penurunan kualitas ekosistem pesisir. Pemanfaatan yang multiuse, mengakibatkan ketidakteraturan dalam pemanfaatan kawasan sehingga 
menimbulkan perubahan fungsi dari ekosistem pesisir yang mengakibatkan penurunan terhadap kualitas ekosistem dan lingkungan.

$$
\text { Pengelolaan pesisir yang }
$$
berfokus pada karakteristik wilayah, dengan menempatkan tiga pilar pembangunan berkelanjutan yaitu ekologi, ekonomi, dan sosial secara proporsional sangat dibutuhkan. Dahuri dkk. (2008) menjelaskan bahwa berdasarkan karakteristik dan dinamika dari kawasan pesisir dan lautan, potensi dan permasalahan pembangunan serta kebijakan pemerintah, maka pencapaian pembangunan kawasan pesisir dan lautan secara optimal dan berkelanjutan hanya dapat dilakukan melalui pengelolaan wilayah pesisir dan lautan yang terpadu. Setiap pengelolaan yang terpadu diawali oleh identifikasi permasalahan yang terjadi di Desa Labuhan Sumbawa, dan merancang model yang dapat mengatasi permasalahan yang terjadi. Penelitian bertujuan untuk mengidentifikasi masalah dan model pengelolaan wilayah pesisir di Desa Labuhan Sumbawa, Kecamatan Labuhan Badas, Sumbawa. Hal ini diharapkan dapat memberikan gambaran tentang identifikasi dampak permasalahan yang terjadi di Wilayah Pesisir Desa Labuhan Sumbawa, sehingga dapat memberikan masukan untuk merencanakan wilayah secara berkelanjutan.

\section{METODE PENELITIAN}

\section{Waktu dan lokasi penelitian}

Penelitian dilaksanakan di Desa Labuhan Sumbawa, Kecamatan Labuhan Badas, Kabupaten Sumbawa, NTB dari bulan Januari sampai dengan Februari 2021.

\section{Pendekatan penelitian}

Penelitian ini menggunakan pendekatan kualitatif deskriptif, dengan jenis penelitian observatif.

\section{Metode pengumpulan data}

Data yang digunakan dalam penelitian ada dua, yaitu data primer dan data sekunder. Data Primer diperoleh dari pengamatan atau observasi secara langsung di lapangan, terkait permasalahan yang terjadi di wilayah pesisir Labuhan Sumbawa (Gambar 1). Data sekunder meliputi literatur, dokumen, serta laporan yang terkait dengan penelitian. Pengumpulan data 
dilakukan dengan metode observasi, wawancara semi terstruktur, dan dokumentasi. Observasi dilakukan di wilayah lokasi penelitian, terkait kondisi fisik lingkungan, sosial ekonomi, dan kelembagaan. Wawancara dalam penelitian dilakukan untuk mendapatkan informasi secara langsung dengan masyarakat dari berbagai unsur mulai pemerintah desa (kepala desa, BPD, LPM, Kepala dusun), tokoh masyarakat, perwakilan kelompok nelayan dan tokoh pemuda. Metode dokumentasi, digunakan untuk menyelidiki buku, majalah, dokumen, peraturan-peraturan. Teknik pengambilan sampel dilakukan secara accidental dilapangan.

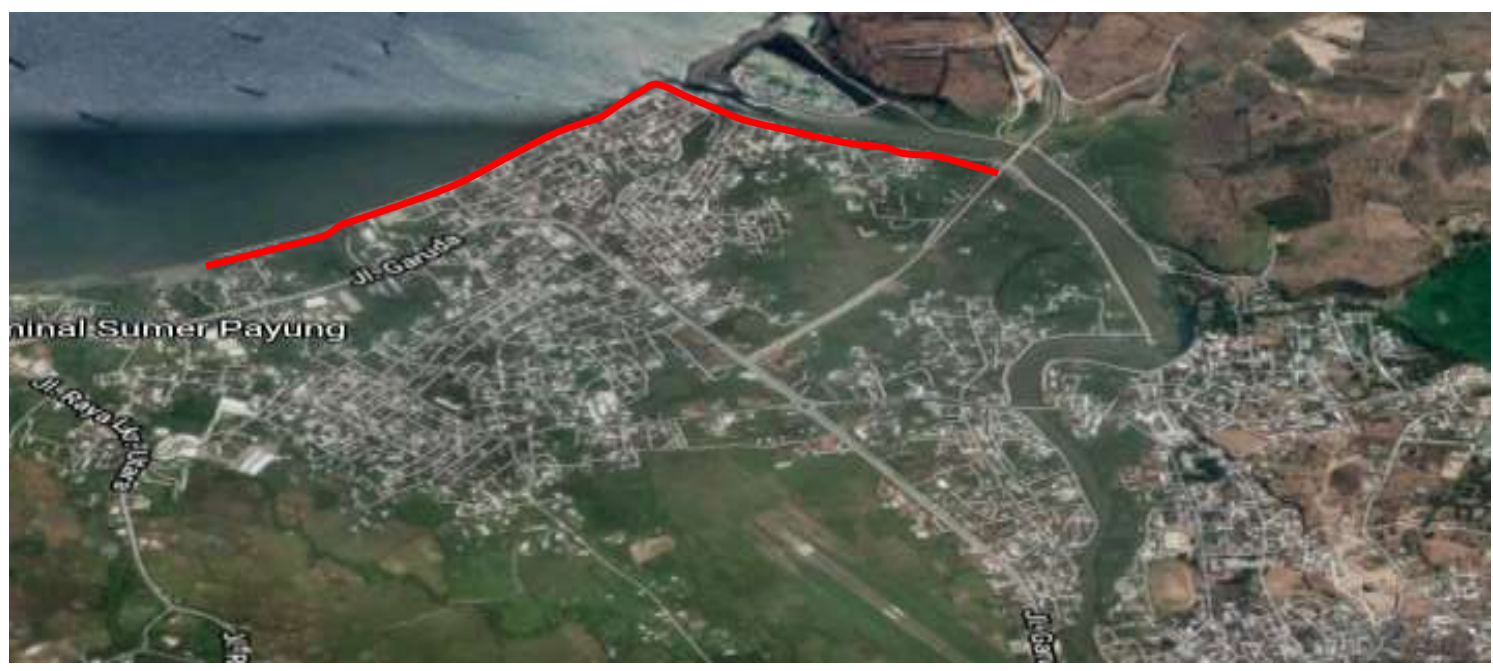

Keterangan: Lokasi pengambilan sampel penelitian

Sumber: Penelitian (2021)

Gambar 1. Lokasi pengambilan sampel penelitian

\section{Analisis data}

Analisis data yang digunakan dalam penelitian, yaitu: Reduksi data (data reduction) merupakan tahap merangkum, memilih hal-hal pokok, memfokuskan pada hal-hal yang penting, bertujuan memberikan gambaran yang jelas dan mempermudah untuk melakukan pengumpulan data. Penyajian data (data display) melalui uraian singkat, bagan, hubungan antar kategori, sehingga akan semakin mudah dipahami. Langkah yang terakhir penarikan kesimpulan (conlusion drawing). 


\section{HASIL DAN PEMBAHASAN}

\subsection{Gambaran Umum Wilayah}

Desa Labuhan Sumbawa merupakan salah satu dari tujuh desa di Kecamatan Labuhan Badas yang terdiri dari enam dusun, yakni Kauman, Olatrarang, Pasir, Kali baru, Padak, dan Griya idola dengan luas 630 Ha. Berada pada ketinggian 2-4 mdpl, dengan topografi berada pada dataran rendah, pesisir, dan aliran sungai dengan tingkat kemiringan tanah $15-20 \%$.

Jumlah penduduk Desa Labuhan Sumbawa Kecamatan Labuhan Badas sebanyak 13.729 jiwa dengan 3.271 Kepala Keluarga (KK) dengan perincian laki-laki 6.480 jiwa dan perempuan 7.249 jiwa. Pola pemanfaatan lahan di wilayah Desa Labuhan Sumbawa pada umumnya merupakan permukiman $(318,57$ $\mathrm{ha} / \mathrm{m}^{2}$ ), sisanya dimanfaatkan untuk lahan persawahan, perkebunan, dan fungsi-fungsi lain. Keberadaan wilayah Desa Labuhan Sumbawa berada dipesisir mempengaruhi jenis pekerjaan masyarakat. Sebagian besar masyarakat labuhan Sumbawa bekerja sebagai nelayan (601 Orang), diikuti oleh pengusaha kecil dan menengah
(467 Orang), dan lainnya. Sebagian besar penduduk Desa Labuhan Sumbawa memiliki pendidikan yang beragam, dengan kategori sedang sekolah (usia 7-18 tahun) berjumlah 1.082 Orang (laki-laki) dan 1.084 Orang (perempuan). Tingginya kategori sedang sekolah menunjukkan bahwa masyarakat Desa Labuhan Sumbawa memiliki kesadaran yang tinggi terhadap pendidikan, selain karena kebijakan dari pemerintah dan keberadaan wilayah desa yang dekat dengan pusat pendidikan. Berdasarkan kondisi kerapatan bangunan permukiman, kepadatan jumlah bangunan hunian, dan kondisi KDB (Koefisien Dasar Bangunan) di Desa Labuhan Sumbawa tergolong padat, memunculkan bangunan kumuh di beberapa dusun.

\subsection{Identifikasi Permasalahan}

Hasil identifikasi permasalahan yang terjadi di wilayah pesisir Desa Labuhan Sumbawa terbagi dalam tiga aspek yaitu aspek fisik lingkungan, aspek sosial-ekonomi, dan aspek kelembagaan yang diuraikan sebagai berikut:

a. Fisik dan Lingkungan

Kerusakan ekosistem.

Pembangunan pesisir di Desa 
Labuhan Sumbawa yang dapat mengakibatkan perubahan ekosistem alami menjadi tidak stabil, dan menjadi terganggu kemudian dapat menyebabkan menurunnya fungsi ekosistem secara ekologis dan ekonomis. Salah satunya, yaitu alih fungsi lahan menjadi jaringan jalan, tambak, dan pemukiman Rusaknya ekosistem wilayah pesisir, dapat mengakibatkan terumbu karang dan ekosistem mangrove diperairan menjadi rusak. Bengen dkk. (2011), ekosistem mangrove yang telah beralih menjadi lahan budi daya tambak udang dan tidak berproduksi akan menimbulkan kerusakan seperti terjadinya erosi garis pantai dan sempadan sungai, sedimentasi, pencemaran, berkurangnya fungsi ekologi dan secara langsung akan mempengaruhi fungsi ekonomi dengan berkurangnya jumlah tangkapan nelayan serta terjadinya intrusi air laut. Soraya dkk. (2012), penurunan jumlah produksi ikan dipengaruhi oleh penurunan luasan ekosistem mangrove akibat alih fungsi menjadi tambak dan tidak ada lagi siklus untuk melakukan pemijahan dan berkembang biak, berimplikasi terhadap menurunnya jumlah produksi dan pendapatan nelayan yang berkurang sehingga akan kesulitan untuk memenuhi kebutuhan hidup dan dapat meningkatkan kemiskinan didaerah pesisir. Tain (2011), kerusakan ekosistem menjadi salah satu penyebab semakin langka sumber daya ikan, sehingga akan mengubah perilaku masyarakat menjadi tidak ramah lingkungan.

Kerusakan sumber daya ikan. Sebagian besar masyarakat di Desa Labuhan merupakan nelayan yang memiliki perahu dengan BBM (bahan bakar minyak), dan menggunakan alat tangkap pancing dan jala. Namun penggunaan BBM, kelebihan tangkap dan degradasi lingkungan dari kegiatan perikanan, dapat mengakibatkan perubahan ekosistem perairan. Beberapa jenis alat tangkap berpotensi merubah stabilitas dan keberlangsungan sumberdaya ikan karena penggunaan mata jaring berukuran sangat kecil. Penggunaan bubu ikan, jaring insang lingkar, jala lempar dan ladung penyu di daerah terumbu karang memiliki dampak negatif bagi terumbu karang dan keberlanjutan sumberdaya ikan (Tamarol dkk., 2012).

Pencemaran lingkungan (sampah, 
air, polusi udara, dan kebisingan). Pencemaran lingkungan yang terjadi di Desa Labuhan Sumbawa terjadi karena masukan polutan dari kegiatan aktivitas manusia di sepanjang garis pantai. Sumber utama pencemaran di Desa Labuhan Sumbawa terdiri dari tiga jenis kegiatan, yaitu kegiatan industri kecil, kegiatan rumah tangga, dan kegiatan pertanian. Bahan utama yang terkandung dalam buangan limbah dari ketiga sumber tersebut berupa sampah, sedimen, unsur hara, pestisida, dan organisme patogen. Penumpukkan sampah beberapa lokasi di Desa Labuhan Sumbawa, disebabkan tidak terdapatnya tempat pembuangan sampah. Minimnya ketersediaan bak sampah yang disediakan oleh pemerintah desa sebagai tempat pembuangan sementara dan rendahnya pengetahuan masyarakat terkait penanganan sampah , memicu perilaku masyarakat memanfaatkan laut, sungai, lahan kosong sebagai tempat membuang sampah. Ayu dkk. (2020) menjelaskan bahwa tingginya volume sampah disebabkan oleh kurangnya kesadaran, dan pengetahuan masyarakat dalam pengelolaan sampah di Desa Labuhan Sumbawa. Selain sampah, masyarakat merasakan kondisi lingkungan yang kurang nyaman di sebabkan oleh keberadaan polusi udara dan kebisingan yang terjadi di Desa Labuhan Sumbawa. Polusi dan kebisingan diperparah dengan kondisi desa Labuhan Sumbawa yang gersang. Kondisi tersebut sangat dirasakan oleh masyarakat yang bermukim di Dusun Pasir, Dusun Olat Rarang, dan Dusun Kauman. Polusi udara dan kebisingan adalah salah satu dampak kegiatan PLTD Labuhan Sumbawa yang sangat dirasakan masyarakat desa Labuhan Sumbawa terutama yang bermukim di RT 3 RW 2 (Hartono dkk., 2017).

Abrasi, sedimentasi, dan siltasi. Gelombang laut yang tinggi dapat mengikis daratan secara signifikan. Abrasi yang terjadi di wilayah Desa Labuhan Sumbawa dapat merusak dan mengancam bangunan-bangunan yang berbatasan langsung dengan air laut. Proses abrasi yang terjadi menyebabkan wilayah semakin berkurang sehingga upaya pemerintah daerah dilakukan dengan memasang tanggul di sempadan sungai yang dapat mengurangi banjir sewaktu abrasi. Selain itu, kondisi wilayah yang rendah mudah mengalami 
genangan rob. Abrasi atau erosi adalah kerusakan garis pantai akibat dari terlepasnya material pantai, seperti pasir atau lempung yang terus menerus di hantam oleh gelombang laut atau dikarenakan oleh terjadinya perubahan keseimbangan angkutan sedimen di perairan pantai atau hilangnya daratan di wilayah pesisir (Munandar\&Kusumawati, 2017).

Banjir. Kejadian banjir yang terjadi setiap tahunnya berdampak terhadap lingkungan sekitar di Desa Labuhan Badas utamanya di Dusun Padak dan Dusun Griya Idola. Sampah yang menumpuk di bagian sungai terbawa sampai ke pantai. Tingginya sadimentasi berdampak terhadap pendangkalan pada muara sungai.

\section{b. Aspek Sosial Ekonomi}

Permasalahan sosial yang terjadi pada wilayah pesisir adalah kondisi SDM mayarakat nelayan yang mayoritas masih kurang baik. Hal ini disebabkan oleh rendahnya pendidikan formal yang sebagian besar disebabkan oleh sulitnya sekolah. Kurangnya pendidikan berdampak terhadap sulitnya masyarakat nelayan untuk menerima transfer ilmu maupun transfer teknologi sehingga berimplikasi kurangnya pemahaman terhadap nilai sumber daya wilayah pesisir. Pendidikan dapat merubah perilaku warga sasaran dalam memahami sumberdaya pesisir (Hartono dkk., 2020).

Permasalahan ekonomi yang terjadi adalah akibat: kemiskinan nelayan, keterbatasan modal, kesulitan BBM, dan industri yang tidak berkembang. Akar permasalahan dari kemiskinan nelayan sendiri disebabkan oleh: a) Kondisi Alam. Musim paceklik yang selalu datang tiap tahun dengan durasi waktu yang tidak menentu serta persoalan banjir yang kerap melanda desa Labuhan Sumbawa, membuat masyarakat pesisir desa Labuhan Sumbawa hidup dalam suasana ketidakpastian alam dalam menjalankan usahanya sehingga semakin memperparah tingkat kemiskinannya; 2) Tingkat pendidikan.Tingkat pendidikan masyarakat pesisir desa Labuhan Sumbawa berbanding lurus dengan teknologi yang digunakan dalam menjalankan usahanya, dalam hal ini teknologi penangkapan dan pengolahan ikan. Kualitas sumber daya manusia rendah sehingga 
produktivitas hasil tangkapan dan variasi produk olahan yang dihasilkan juga rendah. Saat ini, penangkapan dan pengolahan ikan tangkapan masih dilaksanakan secara tradisional;3) Pola kehidupan. Pendapatan yang diperoleh digunakan untuk memenuhi gaya hidup yang konsumtif dan impulse buying tanpa mempertimbangkan kondisi darurat yang kemungkinan mereka hadapi. Kondisi tersebut menyebabkan posisi tawar masyarakat semakin lemah; 4) Pemasaran hasil tangkapan. Kegiatan pemasaran hasil tangkapan masih dilakukan dengan cara tradisional, sehingga ruang lingkup pemasaran relatif sempit. Beberapa masyarakat nelayan pesisir desa Labuhan Sumbawa menjual hasil tangkapan mereka kepada tengkulak dengan harga yang sangat rendah; 5) Kesulitan modal bagi nelayan juga menjadi kesulitan untuk melakukan usaha penangkapan ikan yang baik.

\section{c. Aspek Kelembagaan}

Kemampuan kapasitas kelembagaan pengawas perikanan masih terbatas, untuk sisi sarana, SDM, maupun dana operasionalnya. Hal ini menjadi salah satu kendala untuk melaksanakan tugas dan fungsinya secara optimal, dengan cakupan wilayah perikanan tangkap yang sangat luas, tentu memerlukan kapasitas kelembagaan pengawasan perikanan yang kuat. Kapasitas kelembagaan penegakan hukum di bidang perikanan tangkap belum kuat, tegas, dan mandiri. Hal ini terjadi, karena pemerintah belum memberikan dukungan penuh kepada lembaga penegakan hukum.

\subsection{Model Pengelolaan Wilayah Pesisir}

Model pengelolaan kawasan pesisir yang dapat diterapkan di Desa Labuhan Sumbawa, antara lain: (1) Pengelolaan tradisional. Model pengelolaan ini diterapkan di pada masyarakat yang masih sangat memegang kepercayaan, adat dan budaya yang berlaku dan memiliki tingkat pengetahuan dan teknologi yang masih rendah, sehingga dibutuhkan campur tangan pemerintah. (2) Pengelolaan sumber daya kawasan pesisir berbasis masyarakat, yaitu model pengelolaan sumber daya ini menjadikan pengetahuan dan kesadaran lingkungan masyarakat sebagai dasar pengelolaan. (3) Co-management. Co-management adalah suatu model 
pengelolaan yang mengakomodasi

kepentingan para stakeholders, dan pemerintah memberikan wewenang kepada masyarakat untuk ikut mengelola sumber daya.

Pengelolaan sumber daya perikanan berbasis ekosistem (Ecosystem Based Fisheries Management/EBFM). merupakan model pengelolaan sumber daya perikanan dengan cara memanfaatkan hasil ekosistem kelautan bertujuan agar terjadi keseimbangan antara berbagai kebutuhan masyarakat dan memperkirakan kepentingan generasi di masa mendatang.

\section{KESIMPULAN}

Kerusakan wilayah pesisir akan berdampak terhadap kondisi ekologi, ekonomi, dan sosial. Mitigasi risiko dan investigasi yang menyeluruh sesuai dengan kondisi riil sangat penting dalam menentukan model pengelolaan yang tepat dan pelibatan multipihak sangat penting dalam pengelolaan wilayah pesisir yang berkelanjutan. Penggunaan berbagai pendekatan yang dilakukan harus terhubung dan terintegrasi dengan grand design pengelolaan tata ruang Kabupaten Sumbawa.

\section{Daftar Pustaka}

Ayu.I.W. Hartono, Y., Mardhia, D., Ayu.I,W., $\quad$ Masniadi,R. Fitriyanto ,S., Kusumawardani, W., Syafruddin. 2020., Penyuluhan Pengelolaan Sampah Perkotaan Berbasis Rumah Tangga di Desa Labuhan Sumbawa. Abdimas Mahakam Journal, 4 (01).

Bengen, D. G., D. Widiarso., M. Ibrahim., dan M.A. Suprapto. 2011. Mangrove Delta Mahakam. Penerbit P4L. ISBN 978-979-19034-5-5.

Dahuri, R., J, Rais, S.P. Ginting., M.J. Sitepu. 2008. Pengelolaan sumber daya wilayah pesisir dan lautan secara terpadu. PT. Pradnya Paramita, Jakarta

Hartono, Y., Mardhia, D., Ayu.I,W., \& $\quad$ Masniadi,R. 2020. Pengelolaan dan Pemanfaatan Sampah Berbasis Rumah Tangga. Literasi Nusantara, Batu. ISBN: 9786236841532.

Hartono, Y., Mardhia, D., Ayu.I,W. Kautsari,N., \& Tawaf., N. 2017. Social Mapping dan Need Assesment (Pemetaan Masyarakat di Sekitar Area PLN Sumbawa). Literasi Nusantara, Batu. ISBN: 9786236841419.

Hou, X., Liu, J., Song, Y., Li, X. (2016). Environmentalecological Effect of Development and Utilization of China's Coastline and Policy Recommendations. Bull. Chin. Acad. Sci. 2016, (31), 1143 1150.

Huang, X. (2016). Resource Economics; Nanjing University Press: Nanjing, China, Volume $1-3$.

Li, J., Ye, M., Pu, R., Liu, Y., Guo, Q., Feng, B., Huang, R., He., G. (2018). Spatiotemporal Change Patterns of Coastlines in 
Journal of Aquaculture Science

DOI: https://doi.org/10.31093/joas.v6i1IS.160
July 2021 Vol 6 Issue Spesial: 77-89

Online pada http://joas.co.id

Zhejiang Province, China, Over

the Last Twenty-Five

Years. Sustainability, 10 (477).

Liao, T.,Cai, T., Liu, Y., Xia, X. 2016.Continental shoreline change in Zhejiangduringthe last one hundred years. J. Mar. Sci , 34, 25-33.

Mujabar, P.S., Chandrasekar, N.(2012). Shoreline change analysis along the coast between Kanyakumari and Tuticorin of India using remote sensing and GIS. Arab. J. Geosci, ( 6) 647-664.

Munandar \& Kusumawati, I. 2017. Studi Analisis Faktor Penyebab Dan Penanganan Abrasi Pantai Di Wilayah Pesisir Aceh Barat. Jurnal Perikanan Tropis, 4(1).

Pemerintah Desa Labuhan Sumbawa. 2020. Profil Desa dan

Kelurahan. Pemerintah Desa Labuhan Sumbawa. Sumbawa.

Pemerintah Indonesia. 2007. UndangUndang Nomor 27 Tahun 2007 tentang Pengelolaan Wilayah Pesisir dan Pulau-Pulau Kecil.Jakarta.

Salmon, C., Duvat, V., Laurent, V.(2019). Human- and climatedriven shoreline changes on a remote mountainous tropical Pacific Island: Tubuai, French Polynesia. Anthropocene, 25, 100191.

Sandhyavitri, A., Fatnanta, F., Husaini, R.R., Suprayogi, I. Combination of a Coastal Vulnerability Index (CVI) and social economic approaches in prioritizing the development of Riau Coastlines, Indonesia; Proceedings of the MATEC Web of Conferences, Bali, Indonesia, 24-25 October 2018, EDP Sciences: Les Ulis, France, Volume 276, p. 02006.

Sener, E., Davraz, A., Şener, S. (2009). Investigation of Aksehir and Eber Lakes (SW Turkey)

Coastline Change with

Multitemporal Satellite

Images. Water Resour.

Manag, 24, 727-745.

Soraya, D., O.Suhara dan A Taofiqurohman. 2012. Perubahan Garis Pantai Akibat Kerusakan Hutan Mangrove di Kecamatan Blanakan dan Kabupaten Subang. Jurnal Perikanan dan Kelautan, 3 (4), 355-364.

Sui, L., Wang,J., Yang, X., Wang, Z. 2020. Spatial-Temporal Characteristics of Coastline Changes in Indonesia from 1990 to 2018. Sustainability 2020, 12(8), 3242. https://doi.org/10.3390/su12083 242.

Sun, X., Wu, M., Tian, J., Lu, J., Yu, H., Song, F., Liang, F. (2019). Driving forces and spatiotemporal variation of Weihai coastline in recent 30 years. $\mathbf{J}$ Appl. Oceanogr, 38, 206-213.

Switzer, A.D., Sloss, C.R., Horton, B.P., Zong, Y.Q. (2012). Preparing for coastal change Introduction. Quat. Sci Rev, (54)1-3.

Tain, A. 2011. Penyebab Kemiskinan Rumah Tangga Nelayan di Wilayah Tangkap Lebih Jawa Timur. Humanity, 7 (1), 1-10.

Tamarol, J., Luasunaung,A., Budiman., J. 2012. Dampak Perikanan Tangkap Terhadap Sumberdaya Ikan dan Habitatnya di Perairan Pantai Tabukan Tengah Kepulauan Sangihe Jurnal Perikanan Dan Kelautan Tropis, 8(1).

Wang, B., Liang, L., Hui, F., Cheng, X., Gong, P., Chen, Z.; Huang, H. Spatiotemporal changes of the Chinese coastlines: Landsat imagery from 1975 to 2015 . J. Kecamatan Legonkulon, 
Beijing Norm. Univ. Nat. Sci. 2019, 55, 83-100.

Zhu, G., \& Xu, X. (2012). Annual Processes of Land Reclamation from the Sea Along the Northwest Coast of Bohai Bay During 1974 to 2010. Sci. Geogr. Sin. 32, 1006-1012. 